\title{
Transformative high-tech solutions leverage ANR response
}

A s we go to press with this issue, the scope of the catastrophe in Japan grows as events continue to unfold. The human suffering, economic damage and environmental consequences will command global attention, effort and resources of historic proportions. In this context, any editorial comment on the issues facing California's agriculture and natural resources seems inappropriate. On the other hand, global events are sobering reminders of the importance of our commitment to healthy food systems, environments, communities and Californians.

In the last issue's editorial, Vice President Dan Dooley described systemic and environmental challenges to the global food system, as well as the risk of regional natural disasters and resulting environmental, economic and human impacts. There can be no argument that both short and long term, the response to the events in Japan, New Zealand, Haiti and elsewhere must and will be global, affecting us all directly and indirectly.

For California Agriculture, we recognize that while our role is small in the short term, the long-term importance of the issues-focused research that we publish is not. We are also aware that expanding access to and speeding the publication of policy-relevant science from the University of California is both imperative and possible.

Last year at this time, I wrote about successful efforts, coordinated by Executive Editor Janet White, to digitize, index and post online the entire library of California Agriculture's 64-year history. The immediate impact of that effort resulted in millions of page views and has information and programs. In the near future, we envision integrated web-based and mobile electronic tools, resources and applications that will provide ready access to existing UC digital repositories and research data, along with an array of locationaware applications (apps) enabled by geographic information systems. These tools will support UC researchers and educators, gather critical data and deliver site-specific information almost anywhere or anytime.

UC academics are already delivering tools that illustrate what is possible. For example, Maggie Kelly, UC Berkeley cooperative extension specialist, has led the development of a free smart-phone app that allows users to report oak trees displaying the symptoms of sudden oak death, a disease causing significant damage to California's oak species. While Kelly's app and related website, OakMapper.org, help scientists study the disease, they also enable involved citizens to contribute important data in real time directly to research databases.

In another example, Anthony O'Geen, UC Davis cooperative extension specialist, has created a smart-phone app that exploits the device's GPS (global positioning system) capabilities to provide location-specific information on soil type, composition and other characteristics.

Likewise, Matthew Fiedelibus, associate cooperative extension specialist at the UC Kearney Agricultural Center near Fresno, is exploiting the capabilities of an array of so-

continued to grow. Since then, the evolution of electronic publishing has accelerated rapidly while the current economic situation has constrained our ability to immediately print all of the research that has passed rigorous, anonymous peer review.

In response, we will soon accelerate our electronic publishing efforts at California Agriculture to provide authors the option of fast-track, electronic-only publication of peer-reviewed research. Providing the rapid turnaround of time-sensitive findings increases the journal's value to academic and lay audiences alike and builds the division's electronic reach through California Agriculture's presence in multiple indexes, databases and repositories.

In addition to benefitting to the academic and scientific community, our ongoing expansion of electronic publishing is helping us to define and implement a much broader vision of providing UC research and outreach cial media to speed communication within growing communities of raisin, table and wine grape producers and distributors, pest control advisers, and agency scientists in this important industry.

These and other efforts demonstrate the potential of web and mobile technology to deliver powerful, integrated tools that deliver UC resources and support a range of UC academics and programs, from today's issue of California Agriculture alongside 65 years of indexed articles to the latest report of a new invasive pest.

We all face the challenges of responding to natural disasters, daunting economic realities and seemingly intractable problems, both public and private. For us, publishing and providing greater access to good science and leveraging the power of transformative technology are privileges and passions and, we hope, things that makes a difference. 